\title{
Therapeutic drug monitoring - antiepileptic drugs
}

\author{
M. J. Eadie \\ Department of Medicine, University of Queensland, Brisbane, Australia
}

\begin{abstract}
Aims To provide a brief critical review of the basis and contemporary practice of monitoring the concentrations of antiepileptic drugs in biological fluids.

Methods The review is based on literature data and observations from clinical practice. Results As experience has accumulated, monitoring of antiepileptic drug concentrations has come to be applied mainly to certain of the drugs when present in whole plasma. For these drugs there is a reasonably established relationship between drug concentrations and biological effects, but attention still needs to be paid to issues such as the timing of the measurements in relation to drug intake, the presence or absence of steady-state conditions, the presence in plasma of active metabolites and possible nonlinear pharmacokinetics of particular agents, e.g. phenytoin.

Conclusions Plasma antiepileptic drug concentration monitoring is coming to be used in a more thoughtful and critical manner. Lack of adequate knowledge of matters such as the relationship between the plasma concentrations and antiepileptic and toxic effects of the drugs, not only the newer, but also the longer established ones, in particular clinical situations, remains more important than deficiencies in analytical methodology in limiting the clinical usefulness of antiepileptic drug concentration monitoring.
\end{abstract}

Keywords: antiepileptic drugs, therapeutic drug monitoring

\section{Introduction}

Monitoring of plasma or serum (or sometimes, in earlier years, whole blood) concentrations of the older antiepileptic drugs phenobarbitone and phenytoin began to come into use in the late 1960s, initially as a research procedure which seemed as if it might find a future application in the management of epilepsy. What began in a quite small and exploratory way rapidly expanded into an established analytical laboratory activity of some magnitude, probably sometimes utilized by clinicians because it was possible to do so rather than because it was clinically necessary for them to have the data it could provide. This expansion in monitoring occurred too quickly for the virtues and the limitations of the approach to be explored as thoroughly as they ideally should have been before the method came into widespread use. At the present time monitoring of plasma antiepileptic drug concentrations appears to be requested a little less frequently than in the recent past and to be settling into a more balanced and cost-effective pattern of use after its initial phase of

Correspondence: Professor M. J. Eadie, Department of Medicine, University of Queensland, Brisbane, Australia. exuberant utilization [1-51]. Increasing numbers of more discriminating prescribers are coming to appreciate when monitoring is likely to yield useful information, and is therefore indicated, and when it is likely to prove fruitless.

Plasma concentration monitoring is now widely used not only for phenobarbitone and phenytoin, but for the other longer established antiepileptic drugs carbamazepine, valproate and ethosuximide and also sometimes for primidone, clonazepam and sulthiame. For various reasons, monitoring plasma concentrations of the last three drugs is relatively unimportant. Primidone is biotransformed to phenobarbitone, and steady-state measurement of plasma concentrations of the latter provide a satisfactory guide to the antiepileptic effect of the parent drug [6]: plasma clonazepam concentrations do not correlate closely with the biological effects of the drug, and may not correlate at all [7], and sulthiame has largely disappeared from use. Except possibly for lamotrigine, the antiepileptic drugs that have been marketed in recent years have not yet been subjected to any widespread monitoring in clinical practice.

The account that follows therefore deals mainly with the monitoring of phenobarbitone, phenytoin, carbamazepine, valproate and ethosuximide plasma concentrations. 


\section{Analytical methods}

Originally, plasma phenobarbitone and phenytoin concentrations were measured by ultraviolet spectrophotometry, with or without preliminary derivatization of the drugs [8-11]. The techniques were relatively cumbersome, were sometimes of marginal sensitivity and to various degrees were nonspecific, depending on the efficiency of the preliminary separation stages during extraction of the drug from plasma. Such spectrophotometric methods never came into widespread use and were replaced by chromatographic techniques once these became available. Quantitative thin layer chromatography was little used [12], but gas-liquid chromatography, usually after preliminary derivatization, and later high performance liquid chromatography (h.p.l.c.), provided specific and sensitive assays of the drugs, and sometimes allowed simultaneous measurement of some of their known metabolites. Gas chromatographic-mass spectrometric and h.p.l.c.-mass spectrometric assays permitted enhanced sensitivity and specificity, but the cost of the instrumentation required has largely restricted such methods to research purposes. H.p.l.c. methods remain in use in laboratories which have a relatively low throughput of antiepileptic drug assays and a need to measure a variety of drugs. In busier service laboratories which can afford to dedicate a measuring instrument to the assay of antiepileptic drugs (and perhaps other therapeutic drugs which can be quantified by similar techniques), various immune-assays have usually become the preferred method. These assays utilize a variety of methods of quantitating the in vitro product of a reaction between the drug under study and an antibody raised against it, including radiation measurement, linked enzyme-catalysed reactions [13], liposome lysis [14], fluorescence polarization [15], nephelometric inhibition [16], substrate-labelled fluorescence [17] and electron spin resonance [18]. The immune assays usually offer better economics than h.p.l.c., are convenient and can produce results quite quickly. They are very sensitive, but some of the antibodies used in these methods (or some batches of the antibodies) may cross-react with metabolites of the drug in question, including biologically active metabolites, e.g. carbamazepine-10,11-epoxide in the case of carbamazepine [19]. Hence immune-assays may sometimes yield results which do not coincide with those produced by intrinsically more specific methods, and which may mislead the prescriber if an inactive metabolite is measured as well as the drug in question, particularly if the relative proportions of the two substances are unusual, as may occur if the metabolite accumulates in renal failure, e.g. $p$-hydroxy phenytoin [20], or as result of a pharmacokinetic interaction.

Newer assay methodologies, e.g. micellar electrokinetic capillary chromatography, are beginning to be applied to the antiepileptic drugs [21]. The range of available techniques has been discussed by Hooper \& Johnson [22].

\section{Body fluids in which concentrations may be monitored}

Antiepileptic drug concentrations are usually measured in plasma or serum, in which the concentrations are virtually identical, and most published data relate to concentrations in these fluids. It is perfectly practicable to measure the drug concentrations in whole blood, but the simultaneous drug concentrations may not be identical in red cells and in plasma. For phenytoin, the red cell to plasma concentration ratio is normally $0.23: 1$ [23] and for carbamazepine 0.38:1 [24]. Red cell numbers may therefore influence the interpretation of the whole blood drug concentration values. Also, very few data are available correlating antiepileptic drug concentrations in whole blood with biological effects of the drugs.

The receptor sites at which most antiepileptic drugs act appear to be situated on or close to the surfaces of neurones. The drug concentration in extracellular fluid around these sites determines the drug effect at these sites, and drug molecules in extracellular fluid are in equilibrium with molecules of the drug that are simultaneously present in plasma water. Hence in most instances plasma unbound antiepileptic drug concentrations provide a better measure of potential pharmacological effect than do whole plasma drug concentrations. Ideally, antiepileptic drug unbound concentrations in plasma or serum would always be measured for agents which bind to plasma proteins (Table 1). In clinical practice, it usually proves sufficient to obtain a measure of plasma unbound antiepileptic drug concentration only when there is reason to suspect that the patient's plasma protein binding capacity for the drug may have been altered by changed physiological circumstances (mainly the later stages of pregnancy), by disease (mainly hepatic or renal disorders), by malnutrition or by a drug-drug interaction known to involve competition for plasma protein binding sites. The last remains a largely theoretical possibility in relation to the antiepileptic drugs at present available. Other drugs are known to displace some of the antiepileptic drugs from their plasma protein binding sites in the test tube situation, but in the body redistribution and elimination of the displaced drug makes the interaction of negligible clinical consequence.

Because of the difficulties inherent in dialysis procedures, measurement of plasma unbound drug concentrations often involves a preliminary ultrafiltration step which can introduce its own complications and errors [25-27]. Drug concentrations in the ultrafiltrate, except for nonprotein-bound drugs, will be lower than those in whole plasma, necessitating more sensitive assays for their measurement. Some drug may be lost from the system 
Table 1 Percentages bound to plasma proteins, times to achieve steady-state conditions $\left(\mathrm{t}_{\mathrm{ss}}\right)$ and representative therapeutic range values for antiepileptic drugs.

\begin{tabular}{|c|c|c|c|c|c|}
\hline Drug & $\begin{array}{c}\% \\
\text { protein-bound }\end{array}$ & $\begin{array}{c}\mathrm{t}_{s s} \\
(\text { days })\end{array}$ & Therapeutic rang & $\left(m g l^{-1}\right)$ & Reference \\
\hline Carbamazepine & $72-76$ & $7 \star$ & $16-48$ & $4-12$ & {$[70]$} \\
\hline Clonazepam & 80 & 6 & Not well established & & \\
\hline Ethosuximide & 0 & 10 & $350-700$ & $50-100$ & [71] \\
\hline Gabapentin & 0 & 2 & Not well established & & \\
\hline Lamotrigine & 56 & $5 \#$ & $12-55$ (tentative) & $3-14$ & {$[67]$} \\
\hline Methylphenobarbitone & $59-67$ & & Values for phenobarbitone are more relevant & & \\
\hline Phenobarbitone & 60 & 20 & $60-160$ & $15-40$ & {$[72]$} \\
\hline Phenytoin & $90-93$ & 5 & $40-80$ & $10-20$ & {$[73]$} \\
\hline Primidone & 0 & & Values for phenobarbitone are more relevant & & \\
\hline Tiagabine & 96 & $1-1.5$ & Not well established & & \\
\hline Topiramate & 15 & $4-6$ & Not well established & & \\
\hline Valproate & $85-95$ & $2-3$ & $300-600$ & $50-100$ & [74] \\
\hline Vigabatrin & 0 & 2 & Probably not relevant & & {$[75]$} \\
\hline
\end{tabular}

^This value is calculated from the half-life. In practice the value may be appreciably shorter because of autoinduction of metabolism or longer with new therapy as autoinduction progresses over 2-3 weeks. \# Longer in persons comedicated with valproate, shorter in those comedicated with microsomal enzyme-inducing antiepileptic drugs, e.g. phenytoin.

during ultrafiltration because it binds to the ultrafiltration membrane. It is important not to allow the volume of the ultrafiltrate to become too high relative to that of the original plasma. If this happens, the later stages of the ultrafiltration process may no longer occur at the plasma protein concentration which applied in vivo.

Antiepileptic drug concentrations can be measured in CSF and tears [28, 29] and, except for gabapentin [30], appear to approximate closely to the drugs' unbound concentrations in plasma. Unfortunately, neither fluid is suitable for routine monitoring because of collection difficulties. In saliva, assessment of drug concentration is a little more complex, but the fluid is readily obtainable in sufficient volume, particularly after stimulation, to permit routine antiepileptic drug concentration monitoring without the need for an invasive procedure [30]. The protein concentration in saliva is low enough relative to that in whole plasma to be, in effect, negligible. Therefore saliva drug concentrations should be for practical purposes equal to those in plasma water unless the $\mathrm{pH}$ difference between saliva and plasma causes the concentrations of the proteinunbound nonionized fractions of the drug in the two fluids to differ, or there is an impediment to the unbound drug species equilibrating between the fluids. The effect of $\mathrm{pH}$ difference effect is unimportant for phenytoin and carbamazepine, whilst ethosuximide is unbound in whole plasma and its concentrations in that fluid equal those in saliva [32]. If the $\mathrm{pH}$ is measured once saliva is collected (to avoid evaporation of carbon dioxide, which alters the $\mathrm{pH}$ ), and knowing that plasma $\mathrm{pH}$ is close to 7.4 , the Henderson-Hasselbalch equation can be used to correct for the effects of the $\mathrm{pH}$ difference on the salivary phenobarbitone concentration. Thus a measure of phenobarbitone concentration in plasma water is obtained [33]. Unfortunately, the entry of valproate into saliva does not appear to be purely a matter of passive transport, and measurements of salivary concentrations of the drug do not correlate with its concentrations in plasma [31, 34]. A lack of correlation between salivary and plasma unbound antiepileptic drug concentrations may arise from variation in saliva flow rate $[35,36]$, or if traces of a recent drug dose remain in the mouth when saliva is collected, as they do for up to $2 \mathrm{~h}$ after carbamazepine intake [37].

\section{Sampling times}

The timing of individual sample collections relative to drug intake

In routine monitoring, it is usually understood that the antiepileptic drug concentrations which are measured will be those at minimum steady-state, i.e. trough concentrations, measured in samples collected at the end of the dosage interval. In a given patient, this sampling policy should yield the most consistent concentration values from one dosage interval to the next, because concentrations measured at earlier stages in the dosage interval are more likely to be influenced by variations in drug absorption rate from one oral dose to another. Also, the reference concentration values against which individual measurements in patients are usually compared are those at trough steady-state. In practice, it is often difficult to 
arrange for blood to be collected from patients precisely at the end of a dosage interval, or to be sure that this has been done when concentration values are provided by a laboratory. For the antiepileptic drugs whose concentrations are commonly monitored, steady-state plasma levels will usually be within the range of experimental measurement error of the trough concentration for at least 2 or $3 \mathrm{~h}$ prior to the next drug dose. For more slowly eliminated agents, the values may be within the range of experimental error for considerably longer. In practice, therapeutic range steady-state plasma phenytoin concentrations show only clinically inconsequential fluctuations over $24 \mathrm{~h}$ with once or twice daily drug intake [38]. Steady-state carbamazepine levels may fluctuate rather more [39], and primidone levels, because of the short half-life of the substance, may vary considerably over $12 \mathrm{~h}$, though concentrations of its pharmacologically active metabolite, phenobarbitone, hardly alter [6]. Therefore a degree of latitude in the timing of blood sampling prior to the next dose is usually acceptable in practice when measuring what are intended to be trough drug concentrations. Samples collected between a few minutes and a few hours after drug intake may or may not yield reasonably faithful measures of trough concentrations, depending on how soon drug absorption begins and how rapidly it occurs.

Knowledge of the elimination half-life values of the various antiepileptic drugs allows calculation of the times when steady-state conditions should first apply after the drugs are introduced into therapy, or after their doses are changed, or after their concentrations are altered by drugdrug interactions (Table 1). However, in the case of carbamazepine it is also necessary to also allow time for autoinduction or deinduction of metabolism [40, 41] after any change in drug dosage before steady-state conditions should be assumed. Although a degree of autoinduction of phenytoin metabolism [42] and of valproate $\beta$-oxidation [43] appears to occur, this does not seem sufficient to affect the time to achieve steady-state conditions appreciably. In practice, one usually cannot be certain when steady-state conditions will again apply after a drug dosage change. It is therefore probably better to allow an additional time margin after the predicted time of steady state occurrence before measuring drug concentrations, unless there is a clinical indication for measurement at an earlier stage.

\section{The timing of monitoring during the course of therapy}

The times during the course of the therapy of epilepsy when such trough steady-state antiepileptic drug monitoring will be most appropriately carried out are a matter for clinical judgement. The monitoring is often carried out (i) soon after steady-state conditions are first expected following introduction of the drug in question, (ii) when a completely satisfactory therapeutic response is obtained (i.e. the patient is seizure-free and experiencing no adverse effects, so that a truly 'therapeutic' concentration for that patient is present), (iii) whenever any possible overdosagetype toxic effect occurs, remembering that overdosage may be responsible for quite indefinite symptoms and vague ill health, as well as better recognized unwanted manifestations, (iv) whenever previously well controlled patients relapse, commonly due to failure of compliance on the part of the patient, as mentioned under viii, below, (v) before and after any change in dosage of the drug, and especially for phenytoin, where plasma concentrations increase disproportionately as dose is increased, (vi) before and after any other drug which might interact with the drug of interest is introduced, or withdrawn or has its dosage changed, (vii) intercurrent illness develops, (viii) at random intervals during the course of therapy as an encouragement to compliance, partly by illustrating to the patient that noncompliance and irregular compliance can be detected, and (ix) before withdrawal of therapy after a sufficient period of seizure control, to provide a guide to appropriate dosage if it becomes necessary to resume therapy in the future.

Thus the timing of the monitoring should be determined by the clinical question which it is hoped to answer, or by the clinical dividend which can be obtained from knowing the plasma drug concentration at a particular time. Monitoring carried out at regular intervals in the belief that the successful management of epilepsy depends on maintaining plasma antiepileptic drug concentrations within particular predetermined ranges, in ignorance of the prevailing clinical situation, usually yields limited dividends and on occasion may greatly disadvantage patients.

The pharmacokinetically knowledgeable prescriber should be able to make use of plasma antiepileptic concentration data obtained under other than steady-state conditions, or nontrough steady-state concentrations, as a basis for taking sensible therapeutic decisions. If possible intermittent toxic manifestations occur, e.g. at the expected time of peak plasma drug concentrations after a drug dose, measurement of the drug concentrations at these times is more appropriate than measurement immediately prior to the next dose.

\section{Therapeutic ranges}

The plasma (or serum) therapeutic or 'target' ranges (or therapeutic 'windows') for most of the antiepileptic drugs have been published. There is reasonable agreement between the various recommendations in the literature and ranges such as those shown in Table 1. These ranges do not appear to have been determined by rigorous 
statistical procedures applied to large patient populations. Rather, workers seem to have set the lower limits for each drug at the concentration at which they perceived a reasonable (though usually unspecified) proportion of patients achieved seizure control, and the upper limit at the concentration above which overdosage type adverse effects appear to trouble appreciable numbers of patients, the values then being rounded off to provide a pair of numbers which are reasonably easy to remember. The validity of the idea that there is any clear-cut lower limit to the ranges has been called into question [44]. A few attempts have been made to determine the ranges by more statistically rigid approaches. Thus Stead et al. [45] attempted to define therapeutic ranges by correlating the information about seizure control and other clinical data provided on pathology request forms with plasma drug concentrations, though one might wonder how adequately the seizure control information supplied would have reflected the clinical actualities. These workers found $10 \%$ of subjects whose seizures were controlled by phenytoin had plasma concentrations of the drug below $3 \mathrm{mg} \mathrm{l}^{-1}$, 50\% had levels below $7 \mathrm{mg} \mathrm{l}^{-1}$, and $90 \%$ below $14.7 \mathrm{mg} \mathrm{l}^{-1}$. Eadie [46] used a somewhat similar approach, plotting plasma phenytoin, phenobarbitone and carbamazepine concentrations in patients whose treatment had been under his supervision against cumulative proportion of patients treated whose seizures were fully controlled at these concentrations (Figure 1). In what

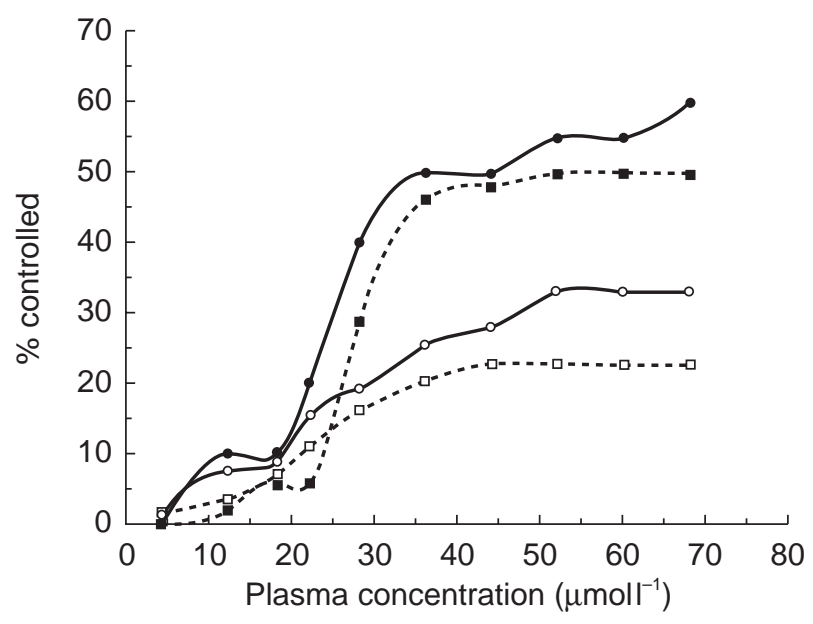

Figure 1 Cumulative percentages of patients treated with carbamazepine and whose seizures were fully controlled for at least 1 year plotted (spline fits) against plasma carbamazepine concentration for 20 patients with generalized epilepsy (continuous line) and 52 patients with partial epilepsy (broken line) who received the drug as monotherapy (upper pair of curves, solid symbols), and for 78 patients with generalized epilepsy and 118 patients with partial epilepsy who received the drug as part of an antiepileptic drug combination (lower pair of curves, open symbols). After [46], reproduced with permission. clearly was a selected population, this approach yielded data correlating drug concentrations with the proportion of all treated patients who achieved known seizure control, rather than with proportions of successfully treated patients only. Thus it yielded probabilities of therapeutic success at different plasma drug concentrations. Admittedly, the outcome of the approach used by Eadie [46] may have been biassed by prior expectations of the likely range of useful concentrations for the drugs, so that attempts were made to achieve these plasma concentrations without waiting for the therapeutic response at lower concentrations to become apparent. Nonetheless, in general it yielded values of the lower and upper limits of useful plasma drug concentrations that were not too dissimilar to the accepted therapeutic ranges for the drugs studied.

There are several ways in which therapeutic ranges could be defined so that they were more useful clinically. A much more rigorous probability based approach to their upper and lower limits could be adopted in sufficiently sized patient populations in whom the degree of seizure control was defined explicitly: such ranges could be determined for particular seizure syndromes, and for patients with different degrees of seizure activity within each seizure syndrome type. There is already evidence that bilateral tonic-clonic seizures are controlled by phenytoin and phenobarbitone [47] or by phenobarbitone [46] at lower plasma concentrations than those required to control partial seizures. Since epilepsy not infrequently goes into remission during treatment, and does not relapse after therapy is withdrawn, it seems likely that, in patients whose disorder remits, the upper and lower limits of the therapeutic range decline as time passes. Another issue to be addressed is whether only total freedom from all seizures, however, minor, should be required for a drug concentration to be regarded as 'therapeutic', or whether the concentration associated with what is considered 'satisfactory' control, or with freedom from major seizures though minor ones continue, is taken as 'therapeutic'? Authors sometimes do not define what they mean by seizure 'control'.

Antiepileptic drugs are sometimes used for indications other than epilepsy, e.g. tic douloureux, myotonia, bipolar affective disorder, prophylaxis of certain varieties of migraine and of cardiac dysrhythmia. There is relatively little good quality information as to whether the therapeutic ranges for epilepsy apply for these other conditions, except that the range for carbamazepine does appear appropriate in treating trigeminal neuralgia [48], and that for phenytoin in cardiac dysrhythmias [49].

Although the therapeutic ranges can provide clinically useful guideposts and initial targets for antiepileptic drug therapy, there is little doubt that they have often been regarded as more than this and perceived in the same light 
as the normal plasma concentration ranges of physiological variables, e.g. the blood glucose concentration. This attitude can lead to unwise additional therapeutic action in already completely satisfactory clinical situations where there is full seizure control in the absence of adverse effects [50]. Therapeutic ranges of plasma concentrations of antiepileptic drugs are good servants in the management of epilepsy, but can become bad masters. If achieving a plasma anticonvulsant concentration in the therapeutic range is considered the sine qua non of treating epilepsy, patients will sometimes benefit, but some will become overdosed or receive higher drug doses than they need for full seizure control. Others will be denied benefit from the higher doses which they would have been able to tolerate comfortably and without harm, even if their plasma drug concentrations were then what were usually regarded as 'supratherapeutic' or 'toxic'. On the other hand, a great deal of time can be saved, and benefit obtained, if the therapeutic range is used as a guide to the treatment of epilepsy, where the sufferer experiences infrequent seizures, before the clinical response has had time to become clear: the use of the range can also assist in determining whether apparent treatment failure is due to underdosage or to noncompliance, and aid in the diagnosis of symptoms which may represent drug overdosage.

\section{Interpretation}

Therapeutic ranges that apply in the healthy may not necessarily be entirely appropriate in disease states or in physiological situations in which the plasma protein binding capacity for the drug in question is reduced, e.g. in liver or renal or gastrointestinal diseases, in the later stages of pregnancy and to a minor extent in the elderly, in all of which circumstances plasma albumin concentrations may be lowered. There is also a risk that renal insufficiency could cause retention of a drug metabolite or an endogenous substance which competes for the plasma protein binding sites of the drug in question, thus raising its plasma water concentration relative to its whole plasma concentration. As explained earlier, if for any reason the plasma protein binding of a drug is suspected of being reduced in a patient, so that its whole plasma concentration may be lowered relative to its concentration in plasma water, it is preferable to obtain a measure of the drug's unbound concentration in plasma and to relate this to the therapeutic range of concentrations of the drug in plasma water, i.e. the therapeutic range values in whole plasma multiplied by the unbound fraction of the drug in normal plasma. Even if this is not done, so long as the clinician is aware that the therapeutic range of the drug in whole plasma will be low for a plasma protein bound drug when plasma albumin levels are reduced, the risk of inappropriate therapeutic decisions should be lessened.

The therapeutic range for valproate is rather wide, and some authors believe there is little correlation between plasma concentrations and antiepileptic effects of the drug [51]. Free fatty acids in plasma may displace valproate from plasma protein binding sites, so that dietary circumstances may alter any relationship which exists between whole plasma valproate concentrations and the biological effects of the drug.

As mentioned above, if intrinsically nonspecific assays are used to measure plasma antiepileptic drug concentrations there is the possibility that a metabolite will contribute to the measurement. If the metabolite has antiepileptic activity, this lack of specificity in the assay may offer some advantage in that more of the total pharmacologically active substance in plasma will be quantified. However, if the metabolite lacks biological activity and accumulates, e.g. in renal insufficiency, a misleadingly high measurement may arise. There will also be potentially confusing discrepancies between specific and nonspecific assays of the substance in question, if different methods of measurement are used on different occasions. It is also possible that different batches of antibody used in immune-assay methods may have different degrees of cross-reactivity towards a drug's metabolite or metabolites. In that case, what is nominally the same assay system may yield inconstant results. This appeared to happen some years ago when plasma phenobarbitone concentrations were measured in patients taking methylphenobarbitone when using a phenobarbitone assay in which at least one antibody batch appeared to cross-react with methylphenobarbitone, whereas its successor did not. The clinician who utilizes plasma antiepileptic drug monitoring needs to be aware of such seemingly purely technical issues.

On the other hand, if a specific assay is used and an active metabolite forms in the body and is not measured, the concentration of the parent drug may sometimes mislead the unwary clinician. This can happen if an agent such as primidone, with a relatively short half-life, has its steady-state trough concentration measured, and the simultaneous concentration of its metabolite phenobarbitone is ignored. Primidone concentrations may be quite low at this stage of the dosage interval, yet phenobarbitone concentrations usually will be several times greater and probably provide a much better measure of the antiepileptic effect. Interactions that increase plasma carbamazepine-epoxide concentrations relative to simultaneous plasma carbamazepine concentrations, e.g. when phenytoin, phenobarbitone or valproate is added to carbamazepine therapy, may also mislead the unwary clinician if only plasma carbamazepine concentration data are available. Indeed, if the patient is comedicated 
with phenytoin, the prescriber may be better working to a plasma carbamazepine concentration therapeutic range of $15-30 \mu \mathrm{mol}^{-1}$ (4-8 $\mathrm{mg} \mathrm{l}^{-1}$, rather than the more conventional 25-50 $\mu \mathrm{mol} 1^{-1}$, i.e. 6-12 $\left.\mathrm{mg} \mathrm{l}^{-1}\right)$.

Enantiomer-specific assays are not a consideration in relation to the longer-established antiepileptic drugs discussed above, except for ethosuximide, whose plasma enantiomer concentration ratios remain constant across the dosage interval [52], so that the concentration of the racemate suffices for clinical purposes. However, such assays could become an issue if plasma vigabatrin concentrations were to be measured as a guide to therapy, because anticonvulsant activity is said to reside in the $[\mathrm{S}]$-enantiomer of the drug. The drug's propensity to cause visual field defects is likely to restrict its use mainly to children with infantile spasms, and in children, though not in adults, the plasma concentration ratios of the drug's two enantiomers differ with time after intake of each dose [53]. Hence, measurement of racemic vigabatrin concentrations in this age group may yield misleading information. However, because [S]-vigabatrin exerts its antiepileptic effect by virtue of irreversible inhibition of $\gamma$-aminobutyrate transaminase, it is argued that a close correlation between the antiepileptic effects of the drug and the plasma concentrations of the enantiomer should not be expected. The matter does not seem to have been pursued in practice, at least partly because of the difficulty involved in carrying out enantiomer specific assays, which require the use of chiral chromatographic columns together with GCMS or g.l.c. [54], or h.p.l.c [55].

All the antiepileptic drugs which are cleared to any significant extent by metabolism are liable to pharmacokinetic interactions [56] if other drugs are being taken by the patient. Appropriately timed plasma antiepileptic drug assay before and after any other drug is added to, or removed from antiepileptic therapy, or has its dosage changed, should permit recognition of any such pharmacokinetic interaction. Such concentration changes should occasion no difficulty in interpretation unless, as mentioned above, there is a simultaneous change in the concentration of an unmeasured biologically active antiepileptic drug metabolite. Once new steady-state conditions apply after an interaction, there is no special need for further monitoring until the dose of one or other of the interacting drugs is changed.

\section{Individualization of results}

Data for the average antiepileptic drug daily doses needed to achieve particular steady-state plasma drug concentrations, usually therapeutic range ones, in individual patients, are available (Table 2). These data can assist in prescribing potentially adequate doses of the drugs, though in the final analysis adequacy of therapy must always
Table 2 Typical antiepileptic drug doses required to achieve mid-therapeutic range plasma concentration values in adults, except where indicated. Values cannot be given for drugs whose therapeutic ranges have not yet been established. It should be appreciated that some patients may not tolerate the full dosage suggested below at the outset of therapy, and that this dose may have to be achieved in several stages over some days or weeks.

\begin{tabular}{lcc}
\hline Drug & $\begin{array}{c}\text { Dose } \\
\left(\mathrm{mg} \mathrm{kg}^{-1} \mathrm{day}^{-1}\right)\end{array}$ & $\begin{array}{c}\text { Age group } \\
(\text { years })\end{array}$ \\
\hline Carbamazepine & 15 & $<11$ \\
Clonazepam & 9 & $>14$ \\
Ethosuximide & 0.15 & \\
Methylphenobarbitone & 30 & $<15$ \\
& 7.5 & $15-40$ \\
Phenobarbitone & 6.5 & $>40$ \\
& 4 & $5-14$ \\
Phenytoin & 4.5 & $>40$ \\
Valproate & 3 & $<13$ \\
& 2.5 & $>13$ \\
\hline
\end{tabular}

be decided on clinical grounds, and not on plasma drug concentration values. There are also data available relating change in steady-state plasma drug concentrations in the individual to drug dosage alterations [57, 58]. Such information is very important in adjusting drug dosage because, for several antiepileptic drugs, steady-state plasma levels do not change in simple linear proportion to the magnitude of dosage alterations. Most of the available data apply to phenytoin where elimination follows MichaelisMenten rather than simple linear kinetics [59], but some information is available for phenobarbitone itself [32], phenobarbitone derived from methylphenobarbitone [32], carbamazepine [60], clonazepam [61], ethosuximide [61] and valproate [62]. A number of nomograms, commonsense and Bayesian type methods for adjusting phenytoin dosage to achieve particular predetermined steady-state plasma concentrations have been published [43]. These approaches are useful, particularly in reducing the risk of overdosage after phenytoin dosages are increased, but as prescribers who appreciate the consequences of the nonlinear elimination kinetics of the drug become experienced in using phenytoin they soon learn to adjust its dosage without recourse to such aids.

\section{Cost-effectiveness}

Aspects of this matter have been considered elsewhere [63]. Antiepileptic drug concentration monitoring 
employing one of the various immune-assay techniques is relatively inexpensive, and h.p.l.c. assays are not overly costly, particularly if they can be carried out in batch mode and especially if the patient is taking multiple antiepileptic drugs whose concentrations can be measured simultaneously. An appreciable proportion of the cost of assays may derive from the blood collection and handling stages. The benefits of the monitoring lie in enhanced efficiency of antiepileptic treatment, with more rapid achievment of satisfactory drug dosage, fewer and earlier recognized overdosage-type adverse effects and more readily detected noncompliance with therapy. Such advantages collectively lead to better control of epilepsy and probably result in a greater chance of the disorder going into remission. The cost-effectiveness of the overall process is enhanced if the monitoring is not employed whenever the opportunity presents but is used discriminatingly in a strategically targeted fashion to answer clinically relevant questions and to resolve or anticipate problems in management, and particularly if the clinician who utilizes the information produced by the monitoring is knowledgeable in pharmacokinetics.

It is also possible that experience acquired in managing epilepsy with the aid of monitoring the plasma concentrations of antiepileptic drugs may itself allow prescribers to become more skilled in treating patients without the need for such monitoring. This phenomenon may be the basis of the finding in the recent Italian Multicentre Trial [64] that there was very little differences in the outcomes of newly diagnosed epilepsy, whether or not monitoring was utilized.

\section{New drugs which may require monitoring}

With the possible exception of vigabatrin, as discussed above, there would seem to be at least theoretical justification for monitoring the plasma concentrations of the antiepileptic drugs introduced into therapeutics in the past decade, and those likely to be introduced, e.g. lamotrigine, gabapentin, topiramate, oxcarbazepine (or its more slowly eliminated 10-hydroxy derivative), tiagabine, levetriacetam and zonisamide: felbamate, because of its toxicity, may never achieve enough widespread use to make its monitoring economically viable. So far, these drugs have been used mainly in combination therapy in persons with refractory seizure disorders. When they are used in combination in treating difficult-to-control epilepsy at least one other antiepileptic substance is also present in the biological system to confound the interpretation of any correlation between plasma concentration and clinical effect. Until they are used reasonably widely as monotherapy in recent onset epilepsy it will be difficult to determine their therapeutic and toxic concentration ranges. Without this knowledge, the prescriber has no soundly based data against which to interpret their plasma concentration values [65]. Notwithstanding, therapeutic ranges have already sometimes been quoted for such drugs, e.g. the $2-4 \mathrm{mg} 1^{-1}$ value cited for lamotrigine [66], though a value of $3-14 \mathrm{mg} 1^{-1}$ has been suggested more recently [67].

\section{The future}

The possibilities of saliva as a vehicle in which to carry out noninvasive monitoring of concentrations of those antiepileptic drugs for which the fluid is a suitable medium for their measurements warrant further exploration, particularly in children or if monitoring needs to be done frequently. Such monitoring opens the prospect of strategically timed self-collection of the fluid by the patient in his or her home, e.g. immediately after a seizure or at the times of occurrence of intermittent symptoms [68, 69].

Advances in analytical methodology in the future may make plasma antiepileptic drug monitoring simpler, faster and cheaper than it is at present, but the methodology already is reasonably efficient and relatively satisfactory. The major problems that need to be remedied are the lack of sufficient high quality plasma drug concentrationbiological effect correlative data, and prescribers without sufficient pharmacokinetic awareness and clinical expertise to allow the data which can be obtained with existing methods to be put to optimal use.

\section{References}

1 Beardsley RS, Freeman JM, Appel FA. Anticonvulsant serum levels are useful only if the physician appropriately uses them: an assessment of the impact of providing serum level data to physicians. Epilepsia 1983; 24: 330-335.

2 Chadwick DW. Overuse of monitoring of blood concentrations of antiepileptic drugs. Br Med J 1987; 294: 723-724.

3 Dodson WE. Level off. Neurol 1989; 39: 1009-1010.

4 Mattson RH. Antiepileptic drug monitoring: a reappraisal. Epilepsia 1995; 36(Suppl 5): S22-S29.

5 Schoenenberger KA, Tanasijevic MJ, Jha A, Bates DW. Appropriateness of antiepileptic drug level monitoring. JAMA 1995; 274: 1622-1626.

6 Eadie MJ, Heazlewood R, Tyrer JH. How worthwhile is plasma primidone measurement? Clin Exp Neurol 1981; 18: 123-131.

7 Naestoft J, Lund M, Larsen NE, Hvidberg E. Assay and pharmacokinetics of clonazepam in humans. Acta Neurol Scand 1973; 49: 103-108.

8 Buder TC, Makaffee C, Waddell WJ. Phenobarbital: studies f elimination, accumnlation, tolerance and dosage schedules. J Pharmacol Exp Ther 1954; 111: 425-435.

9 Dill WA, Kazenko A, Wolf LM, Glazko AJJ. Studies on 5-5'-diphenylhydantoin (Dilantin) in animals and man. J Pharmacol Exp Ther 1956; 118: 270-279. 
10 Svensmark O, Kristensen P. Determination of diphenylhydantoin and phenobarbital in small amounts of serum. J Lab Clin Med 1963; 61: 501-507.

11 Wallace JE. Spectrophotometric determination of diphenylhydantoin. J Forensic Sci 1966; 11: 551-559.

12 Huisman JW, Van Heycop Ten Ham MW, Van Zijl CWH. Influence of ethylphenacemide on serum levels of other anti-epileptic drugs. Epilepsia 1970; 11: 207-215.

13 Scharpe SL, Cooreman WM, Blomme WJ, Laekeman GM. Quantitative enzyme immunoassay: current status. Clin Chem 1976; 22: 733-738.

14 Kubotsu K, Goto S, Fujita H, et al. Automated homogeneous liposome immunoassay systems for anticonvulsant drugs. Clin Chem 1992; 38: 808-812.

15 Lu-Steffes M, Pitduck GW, Jolley ME, et al. Fluorescence polarization immunoassay. IV. Determination of phenytoin and phenobarbital in human serum and plasma. Clin Chem 1982; 28: 2278-2282.

16 Painter PC, Evans JH, Lyon JM. A rate nephelometric phenobarbital and phenytoin assay: analytical and correlation studies of a new single-point calibration immunoprecipitation inhibition method. Ther Drug Monit 1983; 4: 461-466.

17 Wong P-C, Burd JF, Carrico PJ, Buckler RJ, Thoma J, Boguslaski RC. Substrate-labelled fluorescent immunoassay for phenytoin in human serum. Clin Chem 1979; 25: 686-691.

18 Montgomery MR, Holtzman JR, Leute PK. Application of electron spin resonance to determination of serum drug concentrations. Clin Chem 1975; 21: 1323-1328.

19 Contin M, Riva R, Albani F, Perucca E, Baruzzi A. Determination of total and free plasma carbamazepine concentrations by enzyme multiplied immunoassay. Ther Drug Monit 1985; 7: 46-50.

20 Roberts WL, Rainey PM. Interference in immunoassay measurements of total and free phenytoin in uremic patients: a reappraisal. Clin Chem 1993; 39: 1872-1877.

21 Kataoka Y, Makino K, Oishi R. Capillary electophoresis for therapeutic drug monitoring of antiepileptics. Electrophoresis 1998; 19: 2856-2860.

22 Hooper WD, Johnson LP. Measurement of anticonvulsants and their metabolites in biological fluids. In Antiepileptic Drugs Pharmacology and Therapeutics, eds Eadie MJ, Vajda FJE. Berlin, Springer, 1999: 173-187.

23 Kurata D, Wilkinson GP. Erythrocyte uptake and plasma protein binding of diphenylhydantoin. Clin Pharmacol Ther 1974; 16: 355-362.

24 Hooper WD, DuBetz DK, Bochner F, et al. Plasma protein binding of carbamazepine. Clin Pharmacol Ther 1974; 17: 433-440.

25 Lohman JJ, Merkus FW, Costongs GM, Hegtermans EP, Hooymans PM. Pitfalls in the determination of unbound carbamazepine concentrations in plasma. Pharm Weekbl Sci 1984; 6: 91-95.

26 Zysset T, Zeugin T. Comparison of the Amicon Centrifree micropartition system with the Sartofius SM 13249E Centrisart I device to determine protein free phenytoin concentrations. Ther Drug Monit 1986; 8: 346-351.

27 Mauro LS, Mauro VF. Effect of separator tubes on free and total phenytoin and carbamazepine serum concentrations. Ther Drug Monit 1991; 13: 240-243.

28 Monaco F, Mutani R, Mastropaolo C, Tondi M. Tears as the best practical indicator of the unbound fraction of an anticonvulsant drug. Epilepsia 1979; 20: 705-710.

29 Monaco F, Piredda S, Mastropaolo C, Tondi M, Mutani R. Diphenylhydantoin and primidone in tears. Epilepsia 1981; 22: $185-188$.

30 Ben-Menachem E, Persson LI, Hedner T. Selected CSF biochemistry and gabapentin concentrations in the CSF and plasma in patients with partial seizures after a single oral dose of gabapentin. Epilepsy Res 1992; 11: 45-49.

31 Knott C, Reynolds F. The place of saliva in antiepileptic drug monitoring. Ther Drug Monit 1984; 6: 35-41.

32 Eadie MJ, Lander CM, Hooper WD, Tyrer JH. Factors influencing plasma phenobarbitone levels in epileptic patients. Br J Clin Pharmacol 1977; 4: 541-547.

33 McAuliffe JJ, Sherwin AL, Leppik IE, Fayle SA, Pippenger CE. Salivary levels of anticonvulsants: a practical approach to drug monitoring. Neurol 1977; 27: 409-413.

34 Nitsche V, Masher $H$. The pharmacokinetics of valproic acid after oral and parenteral administration in healthy volunteers. Epilepsia 1982; 23: 153-162.

35 Bartels H, Guenther E, Wallis S. Flow-dependent salivary primidone levels in epileptic children. Epilepsia 1979; 20: 431-436.

36 Kamali F, Thomas SH. Effect of saliva flow rate on phenytoin concentrations: implications for therapeutic monitoring. Eur J Clin Pharmacol 1994; 46: 565-567.

37 Dickinson RG, Hooper WD, King AR, Eadie MJ. Fallacious results from measuring salivary carbamazepine concentrations. Ther Drug Monit 1985; 7: 41-45.

38 Vajda FJE, Merory J, Bladin PF. Fluctuation of plasma phenytoin levels on single dose and twice daily dosage regimes. Proc Austn Assoc Neurol 1975; 12: 61-64.

39 Tomson T. Interdosage fluctuations in plasma carbamazepine concentration determine intermittent side effects. Arch Neurol 1984; 41: 830-834.

40 Bernus I, Dickinson RG, Hooper WD, Eadie MJ. Early stage autoinduction of carbamazepine metabolism in humans. Eur J Clin Pharmacol 1994; 47: 355-360.

41 Bernus I, Dickinson RG, Hooper WD, Eadie MJ. Dose-dependent metabolism of carbamazepine in humans. Epilepsy Res 1996; 24: 163-172.

42 Dickinson RG, Hooper WD, Patterson M, Eadie MJ, Maguire B. Extent of urinary excretion of $p$-hydroxyphenytoin in healthy subjects given phenytoin. Ther Drug Monit 1985; 7: 283-289.

43 McLaughlin DB, Andrews JA, Hooper WD, Cannell GR, Eadie MJ, Dickinson RG. Apparent autoinduction of valproate $\beta$-oxidation in humans. Br J Clin Pharmacol 2000; 49: 409-415.

44 Levine M, Chang T. Therapeutic drug monitoring of phenytoin. Rationale and current status. Clin Pharmacokin 1990; 19: 341-358.

45 Stead AH, Hook W, Moffat AC, Berry D. Therapeutic, toxic and fatal blood concentration ranges of antiepileptic drugs as an aid to the interpretation of analytical data. Human Toxicol 1983; 2: 135-147.

46 Eadie MJ. Plasma antiepileptic drug monitoring in a neurological practice: a 25 -year experience. Ther Drug Monit 1994; 16: 458-468.

47 Schmidt D, Einicke I, Haenel F. The influence of seizure type on the efficacy of plasma concentrations of phenytoin, 
phenobarbital, and carbamazepine. Arch Neurol 1986; 43: 263-265.

48 Tomson T, Tybring G, Bertilsson L, Ekbom K, Rane A. Carbamazepine therapy in trigeminal neuralgia. Clinical effects in relation to plasma concentration. Arch Neurol 1980; 37: 699-703.

49 Bigger JTJ, Schmidt DH, Kutt H. Relationship between plasma level of diphenylhydantoin sodium and its cardiac antiarrhythmic effect. Circulation 1968; 38: 363-374.

50 Woo E, Chart YM, Yu YL, Chart YW, Huang CY. If a stabilized epileptic patient has a subtherapeutic antiepileptic drug level, should the dose be increased? A randomized prospective survey. Epilepsia 1988; 29: 129-139.

51 Kilpatrick CJ, Bury RW, Fullinfaw RO, Moulds RF. Plasma concentrations of unbound valproate and the management of epilepsy. Aust N ZJ Med 1987; 17: 574-579.

52 Tomson T, Villen T. Ethosuximide enantiomers in pregnancy and lactation. Ther Drug Monit 1994; 16: 621-623.

53 Nagarajan L, Schramm T, Appleton DB, Burke CJ, Eadie MJ. Plasma vigabatrin enantiomer ratios in adults and children. Clin Exp Neurol 1993; 30: 127-136.

54 Schramm TM, McKinnon GE, Eadie MJ. Gas chromatographic assay of vigabatrin enantiomers in plasma. J Chromatog 1993; 616: 39-44.

55 Vermeij TA, Edelbroek PM. High performance liquid chromatographic analysis of vigabatrin enantiomers in human serum by precolumn derivatization with $o$-phataldialdehyde- $N$-acetyl-L-cysteine and fluorescence detection. J Chromatog B Biomed Sci Appl 1998; 716: 233-238.

56 Patsalos PN, Duncan JS. Antiepileptic drugs. A review of clinically significant drug interactions. Drug Safety 1993; 9: 156-184.

57 Eadie MJ. Plasma level monitoring of anticonvulsants. Clin Pharmacokin 1976; 1: 52-66.

58 Eadie MJ, Tyrer JH. Anticonvulsant therapy: pharmacological basis and practice. 3rd. edition. Edinburgh: Churchill-Livingstone, 1989.

59 Gerber N, Wagner JG. Explanation of the dose-dependent decline of diphenylhydantoin plasma levels by fitting to the integrated form of the Michaelis-Menten equation. Res Chem Path Pharmacol 1972; 3: 455-466.

60 Cotter LM, Eadie MJ, Hooper WD, Lander CM, Smith MT, Tyrer JH. The pharmacokinetics of carbamazepine. Eur J Clin Pharmacol 1977; 12: 451-456.

61 Eadie MJ, Tyrer JH, Smith GA, McKauge L. Pharmacokinetics of drugs used for petit mal absence epilepsy. Clin Exp Neurol 1977; 14: 172-183.
62 Bowdle AT, Patel IH, Levy RH, Wilensky AJ. Valproic acid dosage and plasma protein binding and clearance. Clin Pharmacol Ther 1980; 28: 486-492.

63 Eadie MJ. Indications for plasma drug monitoring in patients with epilepsy. Implications for reducing costs. Pharmacoeconomics 1997; 11: 343-349.

64 Jannuzzi G, Cian P, Fattore C, Gatti G, Bartoli A, Monaco P, Perruca E. A multicentre randomized controlled trial on the clinical impact of therapeutic drug monitoring in patients with newly diagnosed epilepsy. The Italian TDM Study Group Epilepsy 2000; 41: 222-230.

65 Tomson T, Johannessen SI. Therapeutic monitoring of the new antiepileptic drugs. Eur J Clin Pharmacol 2000; 55: 697-705.

66 Porter RJ. General principles. How to use antiepileptic drugs. In Antiepileptic Drugs 4th edn, eds. Levy RH, Mattson RH, Meldrum BS. New York, Raven Press, 1995: 137-148.

67 Morris RG, Black AB, Harris AL, Batty AB, Sallustio BC. Lamotrigine and therapeutic drug monitoring: retrospective survey following the introduction of a routine service. $\mathrm{Br} J \mathrm{Clin}$ Pharmacol 1998; 46: 547-551.

68 Herkes GK, Eadie MJ. Daily salivary anticonvulsant monitoring in patients with intractable epilepsy. Clin Exptl Neurol 1989; 26: 141-149.

69 Herkes GK, Eadie MJ. Possible roles for frequent salivary antiepileptic drug monitoring in the management of epilepsy. Epilepsy Res 1990; 6: 146-154.

70 Monaco F, Riccio A, Benna P, et al. Further observations on carbamazepine plasma levels in epileptic patients. Neurol 1976; 26: 936-943.

71 Browne TR, Dreifuss FE, Dyken PR, et al. Ethosuximide in the treatment of absence (petit mal) seizures. Neurol 1975; 25: 515-524.

72 Feldman RG, Pippenger CE, Florence ML. The relation of anticonvulsant drug levels to complete seizure control. Epilepsia 1975; 16: 203-204.

73 Kutt $\mathrm{H}$, McDowell F. Management of epilepsy with diphenylhydantoin sodium. JAMA 1968; 203: 969-972.

74 Schobben E, van der Kleijn E, Gabreels FJM. Pharmacokinetics of di-n-propylacetate in epileptic patients. Eur J Clin Pharmacol 1975; 8: 98-105.

75 Ben-Menachem E. Vigabatrin. Chemistry, absorption, distribution, and elimination. In Antiepileptic Drugs 4th edn, eds. Levy RH, Mattson RH, Meldrum BS. New York, Raven Press, 1995: 915-923. 